\title{
Bibliométrie ou Bibliometrics: o que há por trás de um termo?
}

Ana Carolina Momesso

Mestranda do Programa de Pós-Graduação em Ciência da Informação da Escola de Comunicação e Artes da Universidade de São Paulo.

Daisy Pires Noronha

Professora Sênior do Programa de Pós-Graduação em Ciência da Informação da Escola de Comunicação e Artes da Universidade de São Paulo.

http://dx.doi.org/10.1590/1981-5344/2831

Considerando as divergências ainda existentes sobre as origens da Bibliometria, são analisadas as proposições apresentadas pelos dois principais autores citados como criadores do termo: Paul Otlet e Alan Pritchard. Trata-se de uma reflexão acerca da interpretação de cada um dos autores para o termo e considera-se que, embora tendo origens diferentes para a sua proposta, ambos tratavam do mesmo assunto. Assim, pode-se afirmar que foi Otlet quem cunhou o termo.

Palavras-chave: Bibliometria; Bibliografia estatística.

\section{Bibliométrie or Bibliometrics: what's behind a term?}

Considering the divergences about the origins of Bibliometrics, two propositions from the main authors cited as the creators of the term - Paul Otlet and Alan Pritchard - are analyzed. A reflection on each author's interpretation is made and, although their proposal carry different origins, it is considered that both dealt with the same subject. Thus, it can be stated that Otlet coined the term.

Keywords: Bibliometrics; Statistical bibliography.

Recebido em 03.06.2016 Aceito em 18.04.2017 


\section{Introdução}

Embora a Bibliometria seja parte indiscutivelmente importante da Ciência da Informação, ainda há certas divergências sobre seu surgimento. As controvérsias, sobre esse aspecto, podem ser identificadas em textos fartamente citados nos trabalhos que tratam deste assunto. Vanz (2003), por exemplo, afirma que Estivals $(1986)^{1}$ e Pinheiro (1983) ${ }^{2}$ defendem que o termo foi utilizado primeiro por Otlet, enquanto MaciasChapula (1998) e Vanti (2001) afirmam ter sido Pritchard o responsável pela popularização do uso da palavra.

Spinak (1996, p. 34), por sua vez, não exclui nenhuma das duas posibilidades: "O termo bibliometria foi cunhado, segundo alguns autores, em 1969 por Alan Pritchard e, segundo outros, por Paul Otlet, várias décadas antes"'3(tradução nossa).

A questão das origens da Bibliometria já foi comentada décadas atrás. Na ocasião, Fonseca (1973 p. 5) alertava para as omissões de autores de línguas neolatinas nos estudos de estado da arte:

Mais recentemente, outro autor inglês de igual categoria - o Sr. Alan Pritchard - cometeu quatro inexatidões em seu artigo "Statistical bibliography ou bibliometrics?" ao estabelecer a cronologia da utilização da expressão bibliografia estatítica e a autoria da palavra bibliometria.

Foi o falecido Paul Otlet quem, no Traité de documentation (1934) usou pela segunda vez aquela expressão, ao mesmo tempo em que cunhou a palavra correspondente, em língua francesa, a bibliometrics, isto é, bibliométrie.

$[\ldots]$

Por autosuficiência ou ignorância de línguas neolatinas, certos autores ingleses vem omitindo nomes de pioneiros de outros países, em estudos recapitulativos (state-of-the-art reports) dos temas que abordam.

Apesar disso, nos anos subsequentes ao artigo de Fonseca, o reconhecimento de Otlet não se tornou ponto pacífico.

Entretanto, recentemente, em nota intitulada Forgotten founder of bibliometrics à sessão Correspondence do volume 510 da renomada revista Nature, Ronald Rousseau (2014, p. 218) reinvindica para Otlet a criação da Bibliometria. Referindo-se a edição anterior da revista que mencionou Otlet, o autor afirma que além se ser um dos inventores conceituais da internet:

1 ESTIVALS, R. Criação, consumo e produção intelectuais. In: FONSECA, E. N. da (Org.). Bibliometria: teoria e prática. São Paulo: Cultrix, 1986. p. 35-68.

2 PINHEIRO, L. V. R. Lei de Bradford: uma reformulação conceitual. Ciência da Informação, v. 12, n. 2, p. 5980, jul./dez. 1983.

3 No original: "El término bibliometría fue acuñado, según algunos autores, en 1969 por Alan Pritchard y, según otros, por Paul Otlet varias décadas antes". 
[...] o bibliotecário belga Paul Otlet cunhou pela primeira vez o termo "bibliometria". Em seu livro Traité de Documentation (1934), ele invocou a fundação de um novo campo, bibliométrie, que definiu como a medição de todos os aspectos relacionados com a publicação e leitura de livros e documentos.

Como exemplo, Otlet sugeriu registrar a frequência com que um livro ou autor específico é lido. Ele observou que a matemática estava tornando-se cada vez mais importante na maioria dos campos científicos, incluindo a biologia e a sociologia, e sentiu que também deveria ser incluída na Biblioteconomia."4 (tradução nossa).

Não pretendemos discutir as razões pelas quais uma parte da comunidade acadêmica atribui as origens da Bibliometria à Pritchard enquanto outra reconhece o pioneirismo de Otlet. Contudo, acreditamos que a questão merece atenção e nessa oportunidade buscamos identificar as semelhancas e diferenças entre a "Bibliometrics" e a "Bibliométrie".

Para tanto, partimos da proposta de Pritchard que surgere o termo "bibliometrics" como sendo mais adequado para a denominação dos estudos que vinham sendo denomidados como "bibligrafia estatística" e que, em geral, buscavam elucidar o processo de comunicação escrita e a natureza e o curso do desenvolvimento de uma disciplina e/ou demonstrar o movimento histórico para determinar o uso de livros e periódicos em pesquisas.

Elucidar as características da "bibliografia estatítica" pareceu-nos o ponto de partida mais adequado para a discussão. Isso porque, por "bibliografia estatística" cada um dos autores tem interpretação bastante diferente entre si. Assim, apresentamos nossa discussão, buscando compreender a definição de cada autor para "bibliografia estatística" e "bibliometria".

\section{A Bibliografia Estatística e a Bibliometria "Pritchartiana"}

De acordo com Pritchard (1969) o primeiro a usar a expressão "bibliografia estatística" teria sido Wyndham Hulme $(1922)^{5}$, que utilizando-se de dados de Cole y Eales $(1917)^{6}$ produziu trabalhos originais em que observou o crescimento de patentes em relação aos processos sociais no Reino Unido; e mudanças do Catálogo Internacional

\footnotetext{
${ }^{4}$ No original: "[...] the Belgian librarian Paul Otlet first coined the term 'bibliometrics'. In his book Traité de Documentation (1934), he called for the foundation of a new field, bibliométrie, which he defined as the measurement of all aspects related to the publication and reading of books and documents.

As an example, Otlet suggested recording how often a particular book or author is read. He noted that mathematics was becoming increasingly important in most scientific fields, including in biology and sociology, and felt that it should be included in library science as well."

${ }^{5}$ HULME, E. W. Statistical bibliography in relation to the growth of modem civilization. London, 1923.

${ }^{6}$ COLE, F. J.; EALES, N. B. The history of comparative anatomy: part 1 - a statistical analysis of the literature. Science Progress, v. 11, n. 44, p. 578-596, abr. 1917.
} 
de Literatura Científica em relação a alterações dos assuntos de pesquisa e a produção nacional da literatura para o desenvolvimento internacional.

O termo teria sido esquecido por vinte e dois anos até que Gosnell (1944) ${ }^{7}$ utilizou-o num artigo sobre obsolescência da literatura, e somente em 1962 ressurgiria num ensaio crítico de Raisig ${ }^{8}$ acerca dos estudos de citação.

Considerando as aplicações da bibliografia estatística, Pritchard demonstra seu desapontamento com o termo e explica que a natureza dessa insatisfação reside no fato dele ter sido usado quatro vezes em quarenta e seis anos. Para o autor o "termo é grosseiro, não muito descritivo, e pode facilmente ser confundido com estatística em si, ou ainda com bibliografia em estatística" (PRITCHARD, 1969, p. 348 tradução nossa) ${ }^{9}$. Por essa razão sugere o termo "bibliometrics" que, segundo ele, não parecia ter sido antes sugerido por nenhum outro pesquisador da área.

Assim, justifica sua escolha, explicando que "[...] embora essa combinação particular seja um neologismo e, portanto, deva ser tratado com certa desconfiança, ela tem ligações muito próximas com as aceitas e análogas 'biometria', 'econometria' e 'cientometria'” (PRITCHARD, 1969, p. 349 tradução nossa) ${ }^{10}$.

E por fim, afirma esperar "[...] que este termo, Bibliometria, seja utilizado expressamente em todos os estudos que buscam quantificar o processo de comunicação escrita [...]" (PRITCHARD, 1969, p. 349 tradução nossa) ${ }^{11}$.

Como se vê, Pritchard apenas sugeriu um termo que julgou mais adequado a fim de evitar confusões linguísticas possíveis de acontecer com o uso da expressão "bibliografia estatítica".

\section{A Bibliografia Estatística e a Bibliometria "Otletiana"}

Otlet (1934), por sua vez, não usou exatamente a expressão "bibliografia estatística". Em sua obra encontramos definições para estatística e para bibliografia. Quanto à primeira, no item 124.3 intitulado La Statistique, afima que "a estatística do livro se confunde com a bibliometria" (OTLET, 1934, p. 16, tradução nossa) ${ }^{12}$. No entanto, entendemos que é preciso cuidado ao afirmar que aqui ele empregava a expressão "statistique du livre" como equivalente à expressão "statistical bibliography".

A definição de Otlet para bibliografia é bastante diversa daquela que se consolidou na área. Ao descrever a "bibliografia" o autor relembra que o termo remonta aos gregos e se referia à escrita ou a cópia de livros, ou seja, dizia respeito à produção de livros, por isso muitas vezes esteve associada ao estudo da produção dos livros manuscritos. Contudo, para o

\footnotetext{
${ }^{7}$ GOSNELL, C. F. Obsolescence of books in college libraries. Coll. Res. Libs., v. 5, n. 2, p. 115-125, mar. 1944.

${ }^{8}$ RAISIG, L. M. Statistical bibliography in the health sciences. Bull. Med. Lib. Assoc., v. 50, n. 3, p. 450-461, jul. 1962.

${ }^{9}$ No original: "The term is clumsy, not very descriptive, and can be confused with statistics itself or bibliographies on statistics"

${ }^{10}$ No original: "[...] whilst this particular combination is a neologism and therefore to be treated with a certain amount of suspicion, it has very close links to the accepted, and analogous 'biometries', 'econometrics', and 'scientometrics'.

${ }^{11}$ No original: "[...] it is to be hoped that this term BIBLIOMETRICS will be used explicitly in all studies which seek to quantify the processes of written communication [...]".

${ }^{12}$ No original: "La statistique du livre se confond avec la Bibliométrie".
} 
autor, a história da produção do livro (bibliografia) seria apenas uma parte da ciência dos livros (bibliologia).

Mas antes de seguir adiante na discussão é preciso entender que, para Otlet, um termo deve repousar sobre a definição das coisas, por isso, o que antes se entendia por bibliologia ou ciência dos livros encontrava limitações em seu domínio já que a definição de uma ciência se dá a partir da distinção de seu objeto. Assim, a bibliologia diria respeito tão somente a livros; daí ao autor preferir o termo documento por ser mais geral que livro (ou biblion, seu radical de origem) para designar a ciência que trata dos registros do conhecimento humano, isto é, a documentação.

Os princípios da documentação quando relacionados aos livros deveria ser denominado bibliologia ao passo que a bibliografia passava a ser uma das partes da documentação responsável pela descrição e classificação dos documentos. A bibliologia teria relação direta com o fenômeno do livro como produto da lógica e da psicologia, da sociologia e da tecnologia, já que é a inteligência humana quem o cria e assimila seu conteúdo, a tecnologia quem o confecciona, e sobre a sociedade que ele repercute, pois que serve a relacionar duas individualidades e as modificar. Por carregar todas essas características o livro comportaria em si a própria história do conhecimento humano e a bibliologia compreenderia duas ciências distintas: a) a Bibliografia geral, global e sintética, que contém a observação do livro em seu todo, com as comparações e as indicações de que resultam; e b) as ciências bibliológicas parciais e analíticas contendo a observação sucessiva e separada de cada um dos aspectos diversos do livro: a bibliologia econômica, tecnológica, sociológica, estética etc.

A estatística, por sua vez, seria uma forma superior de abordagem em qualquer área do conhecimento. Na interpretação do autor, as medidas se referem aos objetos, fenômenos ou fatos, às relações ou leis e que os elementos observados na bibliologia são, em princípio, suscetíveis de serem mensurados. A medida do livro, portanto, consistiria em reduzir todas as partes de um livro qualquer às partes e elementos de um "livro padrão" e como todo livro contém uma parte da matéria bibliológica geral seria possível estabelecer unidades de medidas possíveis de serem comparadas diretamente com as unidades de medida psicológicas e sociológicas em geral. A bibliologia também deveria reservar um espaço para a matemática porque todas as ciências se não buscam a forma matemática ao menos buscam apoio na matemática como um método complementar de pesquisa e isso ocorre porque a matemática exprime relações lógicas entre os fatos objetivos. No domínio das ciências sociais, por exemplo, a matemática seria um meio de realizar e utilizar a estatística para um sistema de relações exatas com as leis definidas pela sociologia.

Cabe lembrar que a mensuração aplicada à ciência dos livros já havia sido abordada por Otlet anteriormente. Em 1900 o autor teria 
publicado um trabalho sobre a estatística das publicações impressas no mundo $^{13}$ (FONSECA, 1986).

Provavelmente como resultado dessas reflexões anteriores o autor defende que a ciência dos livros deveria encaminhar-se para a introdução da medida em suas investigações, sendo oportuno constituir, num conjunto coordenado, as medidas relativas ao livro e ao documento e a esse conjunto denominou Bibliometria. Assim, afirma: "a Bibliometria será a parte definida da Bibliologia que se ocupa da mensuração ou quantificação aplicada aos livros"14 (OTLET, 1934, p. 14, grifo do autor, tradução nossa).

Como se vê, a Bibliometria na obra de Otlet está inserida na Bibliologia e não na Bibliografia, não se tratando, portanto, de um equivalente à Bibliografia Estatística. Entendemos que o que Otlet apresenta não se limita a um termo mais adequado a uma prática já existente, mas uma parte estruturada da Documentação enquanto ciência.

\section{Considerações Finais}

Como se nota, para Pritchard a "Bibliometria" seria apenas um nome mais adequado para a "bibliografia estatística", enquanto que para Otlet surge de um todo complexo dentro de sua idealização da Documentação apresentada em seu tratado mais de três décadas antes do artigo de Pritchard.

É indiscutível que há grandes diferenças entre o entendimento dos autores sobre a "bibliografia estatística". Contudo, o mesmo não nos pareceu observável entre as definições de ambos para a "Bibliometria". Embora tendo sido originados de lógicas e teorias diferentes entre si os termos "Bibliométrie" e "Bibliometrics" mostraram-se equivalentes.

Desse modo, em nossa interpretação, embora Pritchard relate que depois de certas buscas pelo termo não tê-lo localizado em qualquer trabalho da área e tome para si sua autoria, seja por limitações em sua busca ou desconhecimento da produção em outras línguas que não o inglês, ou ainda por omissão consciente como sugeriu Fonseca (1973), fato é que o termo já existia e sua aplicação em nada diferia do que ele estava propondo. Assim, parece-nos indiscutível ter sido Otlet o criador da Bibliometria.

De certo modo, a proposição de Otlet em relação à Bibliometria se apoia na ideia de que a História não está baseada unicamente em testemunhos, ela se transmite também a partir de coisas nas quais o espírito humano deixou suas marcas e os livros são acumuladores dessa energia espiritual, e como os átomos e as moléculas, permitem a abordagem da realidade intelectual através da História (ZOLTOWSKI, 1952).

\footnotetext{
${ }^{13}$ OTLET, P. La statistique internacionale des imprimes. Bulletin de I'Institut International de Bibliographie, ano 5, p. 109-121, 1900.

${ }^{14}$ No original: "La <<Bibliométrie>> sera la partie définie de la Bibliologie que s'occupe de la mesure ou quantité appliquée aux livres".
} 


\section{Referências}

FONSECA, E. N. da. Bibliografia estatística e bibliometria: uma reivindicação de prioridades. Ciência da Informação, v. 2, n. 1, p. 5-7, 1973. Disponível em: <http://revista.ibict.br/ciinf/article/view/19/19>. Acesso em: 11 abr. 2016.

FOSENCA, Edson Nery da (org.). Introdução. In: Bibliometria: teoria e prática. São Paulo: Cultrix; Edusp, 1986. p.9-15.

MACIAS-CHAPULA, C. A. O papel da informetria e da cienciometria e sua perspectiva nacional e internacional. Ciência da Informação, v. 27, n. 2, p. 134-140, maio/ago. 1998. Disponível em: < http://www.scielo.br/pdf/ci/v27n2/macias.pdf >. Acesso em: 16 jan. 2016.

OTLET, P. Traité de documentation: le livre sur le livre: theorie et pratique. Bruxelas: Mundaneum, 1934. Disponível em: <http://lib.ugent.be/fulltxt/handle/1854/5612/Traite_de_documentation_ ocr.pdf >. Acesso em: 11 abr. 2016.

PRITCHARD, A. Statistical bibliography or bibliometrics? Journal of Documentation, v. 25, n. 4, p. 348-349, 1969.

ROUSEAU, R. Forgotten founder of bibliometrics. Nature, v. 510, p. 218, jun. 2014.

SPINAK, E. Diccionario enciclopédico de bibliometría, cienciometría e informetría. Montevideo: UNESCO, 1996. Disponível em: <http://unesdoc.unesco.org/images/0024/002433/243329S.pdf>. Acesso em: 11 abr. 2016.

VANTI, N. A. P. Da bibliometria à webometria: uma exploração conceitual dos mecanismos utilizados para medir o registro da informação e a difusão do conhecimento. Ciência da Informação, v. 31, n. 2, p .152-162, maio/ago. $2002 . \quad$ Disponível em: <http://www.scielo.br/pdf/ci/v31n2/12918>. Acesso em 11 abr. 2016.

VANZ, S. A. de S. A Bibliometria no Brasil: análise temática das publicações do periódico Ciência da Informação (1972-2002). In: ENCONTRO NACIONAL DE PESQUISA EM CIÊNCIA DA INFORMAÇÃO, 5., Belo Horizonte, 2003. Anais... Belo Horizonte: Escola de Ciência da Informação da UFMG, 2003. Disponível em: <http://enancib.ibict.br/index.php/enancib/venancib/paper/view/1961>. Acesso em: 11 abr. 2016.

ZOLTOWSKI, V. Os ciclos de criação intelectual e artística. In FONSECA, E. N. da (Org.). Bibliometria: teoria e prática. São Paulo: Cultrix, 1986. p.136-206. 